\title{
Ação inibitória do endosperma na germinação in vitro de embrião zigótico de pinhão manso
}

\author{
Inhibitory action of endosperm on in vitro germination of physic nut zygotic embryo
}

\author{
Vespasiano Borges de Paiva Neto ${ }^{*}$ Fernando de Pieri Prando ${ }^{\mathrm{I}}$ Lennis Afraire Rodrigues ${ }^{\mathrm{I}}$ \\ Monica Cristina Rezende Zuffo ${ }^{\mathrm{I}}$ Sebastião Ferreira de Lima ${ }^{\mathrm{I}}$
}

\section{RESUMO}

A busca por protocolos de micropropagação de pinhão manso tem resultado em relatos sobre dificuldades na germinação in vitro de sementes recém colhidas. Nesse sentido, levantou-se a hipótese da dormência estar relacionada com a presença do endosperma. Objetivando investigar a influência do endosperma no desenvolvimento in vitro de embriões zigóticos de pinhão manso, extratos puros e filtrados de endosperma de sementes recém colhidas e armazenadas por 50 e 100 dias foram adicionados ao meio MS, no qual foram colocados embriões zigóticos isolados ou contendo endosperma. Foi possível observar que a presença do endosperma junto ao embrião exerce uma inibição à retomada do desenvolvimento do embrião. Ademais, a adição de extratos do endosperma no meio de cultivo reduziu sobremaneira o desenvolvimento dos embriões, evidenciando que além de provável inibição física, o endosperma pode contribuir com inibidores químicos no processo de germinação. Essas observações estão baseadas no perfeito desenvolvimento dos embriões, quando estes foram adicionados isolados ao meio MS, desprovido do extrato.

Palavras-chave: Jatropha curcas, crescimento, dormência, fisiologia da semente.

\section{ABSTRACT}

Researches on physic nut micropropagation have resulted in reports about difficulties in the process of in vitro germination of fresh seeds, and we hypothesized that this dormancy is related to endosperm presence. Aiming to investigate the influence of the endosperm presence on in vitro development of zygotic embryos of physic nut, pure and filtered extracts of the endosperm of newly harvested and stored seeds for up to 100 days were added to MS medium, in which zygotic embryos were added alone or attached to the endosperm. It was observed that the endosperm presence attached to the embryo seems to establish dormancy to the restart of the embryo development. Moreover addition of endosperm extracts into the MS medium greatly reduced the embryos development, supporting the idea that in addition to probable inhibition physics, the endosperm may contribute to chemical inhibitors in the germination process. All these idea were supported by perfect embryo development when it was added to MS medium without endosperm structure or extract.

Key words: Jatropha curcas, growth, dormancy, seed physiology.

\section{INTRODUÇÃO}

O pinhão manso (Jatropha curcas L.) é uma planta oleaginosa da família Euphorbiaceae e essa espécie tem como destaque sua rusticidade, além de ser perene, tolerante à seca e adaptável a uma vasta gama de ambientes e condições edafoclimáticas (SATURNINO et al., 2005). Esta espécie apresenta muitas atribuições, múltiplos usos e considerável potencial energético, considerando a qualidade e quantidade de óleo em suas sementes, entre 25 a 40\%, superior ao da maioria das oleaginosas utilizadas no mercado de biocombustíveis (ARRUDA et al., 2004). Sendo assim, é explícito o interesse pela espécie para produção de biocombustíveis, entretanto, sua propagação possui problemas que limitam a expansão da cultura, como plantios desuniformes, com uso de sementes, e a necessidade de ramos grandes para obtenção de estacas. Nesse contexto, pesquisas a respeito de multiplicação in vitro da espécie são imprescindíveis (NUNES et al., 2008), inclusive pelo fato da necessidade de protocolos de regeneração eficientes para a obtenção de plantas geneticamente modificadas, como tem sido pesquisado em diversos

'Universidade Federal de Mato Grosso do Sul, Campus de Chapadão do Sul, CP 112, 79560-000, Chapadão do Sul, MS, Brasil. E-mail: vespasiano.neto@ufms.br.*Autor para correspondência. 
países (LI et al., 2008; MISRA et al., 2012). Ademais, pesquisas envolvendo o entendimento da expressão proteica (proteoma) no embrião e endosperma de sementes de pinhão manso têm sido conduzidas (LIU et al., 2009; BOORANASRISAK et al., 2013).

As sementes de pinhão manso possuem, além do embrião como responsável pela formação da nova planta, um endosperma com função nutritiva e o tegumento para proteger as demais estruturas da semente contra estresses bióticos e abióticos. Morfologicamente, o embrião e o endosperma são bastante distintos, pois, enquanto o primeiro tornouse uma estrutura lamelar, o segundo tornou-se hipertrofiado (LIU et al., 2009).

NUNES (2007) observou que a manutenção do endosperma inibe a germinação de sementes imaturas in vitro, o que nos leva à hipótese de que o endosperma seja responsável pelo fornecimento de inibidores que impedem o desenvolvimento do embrião. Pesquisas com endosperma de sementes mostraram que esse tecido inibe a protrusão de radículas de muitas angiospermas (IGLESIAS-FERNÁNDEZ \& MATILLA, 2010). Segundo JØKER \& JEPSEN (2003), sementes de pinhão manso recém-colhidas apresentam dormência e necessitam de um período de repouso pós-colheita antes de germinar. Por outro lado, as sementes secas germinam normalmente sem nenhum pré-tratamento, entretanto, de acordo com SEVERINO et al. (2006), há perda do poder germinativo após alguns meses de armazenamento da semente.

A detecção da presença de inibidores nas sementes de pinhão manso tem fundamental importância, visando ao tratamento das sementes para fins de estímulo à germinação, tanto para à dinâmica de degradação ao decorrer do armazenamento. WINDAUER et al. (2012) afirmam que uma limitação importante para germinação em pinhão manso está relacionada com a alta sensibilidade exibida por essas sementes à escassez de água: esse fator pode não só evitar a germinação por si só, mas também pode atrasar suficientemente a germinação, por permitir a indução de dormência secundária, em caso de exposição prolongada a temperaturas que possam desencadear esse processo. No entanto, MUKHERJEE \& JHA (2009) buscaram, na cultura de embriões zigóticos, uma alternativa para minimizar os efeitos da dormência de sementes e, com isso, facilitar os programas de melhoramento genético da espécie.

O objetivo deste trabalho foi verificar a influência do endosperma na germinação in vitro de embriões de sementes maduras ou armazenadas de Jatropha curcas.

\section{MATERIAL E MÉTODOS}

Obtenção das sementes - Foram utilizadas sementes de pinhão manso provenientes de plantas do banco de germoplasma, estabelecido há quatro anos em área cedida pela Fundação de Apoio à Pesquisa Agropecuária de Chapadão, localizada no município de Chapadão do Sul-MS (Latitude: 1841'33'sul - Longitude: 5240’45"oeste; Altitude: 810m; precipitação média anual: $1850 \mathrm{~mm}$; Temperaturas médias anuais: mínima de 13 e máxima de $28^{\circ} \mathrm{C}$ ). Os frutos foram coletados no período de março a junho de 2011 no estádio maduro (pericarpo amarelo) e, após a colheita, as sementes foram removidas manualmente dos frutos e submetidas ao processo de secagem em ambiente sombreado externo ao laboratório, com temperatura e umidade ambientes. Posteriormente, as sementes foram depositadas em sacos de papel e mantidas à temperatura ambiente do laboratório $\left(27 \pm 3^{\circ} \mathrm{C}\right)$, durante a realização dos experimentos.

Germinação in vitro de pinhão manso com diferentes tempos de armazenamento Foram utilizadas 80 sementes para cada tempo de armazenamento (0, 50 e 100 dias), as quais tiveram o tegumento removido com auxílio de bastão de vidro. Os endospermas de 40 sementes foram macerados em gral de porcelana até produzir uma massa homogênea, utilizando-se álcool etílico (P.A.) como extrator, na proporção de $3,0 \mathrm{~mL}$ para cada $1,0 \mathrm{~g}$ de macerado, seguindo metodologia descrita por OLIVEIRA et al. (2009). Em seguida, o extrato de endosperma obtido foi levado à estufa com circulação forçada de ar por 20 horas, a uma temperatura de $40 \pm 2^{\circ} \mathrm{C}$ para evaporação do etanol presente na amostra. Metade desse extrato de endosperma foi re-solubilizado com água destilada $(9,21 \mathrm{ml}$ de água para $1,0 \mathrm{~g}$ de endosperma) e filtrada a vácuo, utilizando kitassato com papel de filtro (gramatura $80 \mathrm{~g} \mathrm{~m}^{-2}$, maioria dos poros com $14 \mu \mathrm{m}$ ), coletando-se o líquido filtrado para adicioná-lo ao meio de germinação, compondo um dos tratamentos. A outra metade do extrato desidratado foi diretamente adicionada ao meio de germinação, compondo mais um tratamento. Assim, os meios de germinação foram compostos pelos sais e vitaminas MS (MURASHIGE

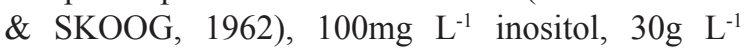
sacarose, $5 \mathrm{~g} \mathrm{~L}^{-1}$ ágar, adicionados do extrato bruto (T1) ou filtrado (T2) do endosperma macerado. Nos demais meios de germinação (T3 e T4), não foram acrescidos extratos de endosperma. Os meios de cultivo foram vertidos em frascos de vidro $(250 \mathrm{~mL})$ contendo $40 \mathrm{~mL}$ de meio já com os respectivos extratos adicionados e tiveram o $\mathrm{pH}$ ajustado em $5,8 \pm 0,1$ antes da autoclavagem $\left(121^{\circ} \mathrm{C}\right.$ e $104 \mathrm{KPa}$ 
por 20min). Os embriões e sementes sem tegumento foram então desinfestados, utilizando imersão dos embriões em hipoclorito de sódio ( $1 \%$ cloro ativo) por $2 \mathrm{~min}$ e etanol $70 \%(\mathrm{v} / \mathrm{v})$ por $1 \mathrm{~min}$; e as sementes sem tegumento em hipoclorito de sódio ( $3 \%$ cloro ativo) por $2 \mathrm{~min}$ e etanol $70 \%(\mathrm{v} / \mathrm{v})$ por $5 \mathrm{~min}$, seguidos de tríplice lavagem com água destilada e autoclavada, já em fluxo laminar.

A inoculação do material vegetal ocorreu da seguinte forma: nos meios de germinação T1 (extrato bruto), T2 (extrato filtrado) e T3 (ausência de extrato), foram inoculados embriões isolados; no meio de germinação T4 (ausência de extrato), foram inoculados os embriões com endosperma intactos (semente sem tegumento). Após a inoculação, os frascos foram mantidos por 30 dias em sala de crescimento sob $16 \mathrm{~h}$ de fotoperíodo, irradiância de $36 \mu \mathrm{mol} \mathrm{m} \mathrm{m}^{-2} \mathrm{~s}^{-1}$ providas por duas lâmpadas fluorescentes tubulares (Luz do Dia Especial, 20W, Osram), e temperatura de $27 \pm 2^{\circ} \mathrm{C}$.

Transcorridos 30 dias da montagem do experimento de germinação, para cada período de armazenamento, foram mensurados os comprimentos da raiz principal e parte aérea das plântulas com auxílio de régua, e também realizada a contagem do número total de folhas (expandidas e em expansão). Os tratamentos constituíram-se de quatro condições de germinação (MS com extrato bruto de endosperma, inoculado com embrião isolado; MS com extrato filtrado de endosperma, inoculado com embrião isolado; Meio MS, inoculado com embrião isolado; Meio MS, inoculado com embrião + endosperma) e três tempos de armazenamento (0; 50 e 100 dias), num fatorial $4 \times 3$, totalizando doze tratamentos. $\mathrm{O}$ delineamento experimental foi inteiramente casualizado com cinco repetições (frascos) por tratamento, em que cada repetição continha quatro estruturas propagativas (embrião isolado ou embrião + endosperma). Os dados resultantes das avaliações foram submetidos à análise de variância e as médias comparadas pelo teste de Tukey $(P=0,05)$.

\section{RESULTADOS E DISCUSSÃO}

A análise de variância (ANOVA) dos parâmetros comprimento da raiz principal e número de folhas das plântulas de pinhão manso mostrou haver diferença significativa para os fatores condições de germinação (endosperma) e tempo de armazenamento das sementes, sem haver interação significativa (Tabela 1). Já para o parâmetro comprimento da parte aérea, além das diferenças significativas detectadas para os fatores condições de germinação (endosperma) e tempo de armazenamento das sementes, a ANOVA mostrou interação significativa entre tais fatores (Tabela 1).

Em trabalhos que envolvem a ação de extratos contendo compostos aleloquímicos, essa diferença de comportamento entre raiz e parte aérea tem sido explicada pelo fato de a raiz ficar continuamente em íntimo contato com o meio de germinação e, consequentemente, com os inibidores, que por sua vez inibem o processo de divisão celular (HOFFMANN et al., 2007; MAGIERO et al., 2009).

Os dados obtidos em todos os parâmetros de crescimento analisados mostram que a presença do endosperma intacto junto ao embrião (T4), em meio de germinação isento de extrato, foi capaz de inibir completamente o processo de germinação, mesmo após 100 dias de armazenamento da semente (Tabelas 2, 3 e 4). Essa resposta sinaliza que o endosperma exerce restrição para retomada do crescimento do eixo embrionário. Essa ideia de inibição fica mais evidente quando observada a resposta do embrião isolado em meio isento de extrato, ou seja, completamente livre dos efeitos do endosperma. Nesse caso, o embrião tornou-se capaz de gerar plântulas morfologicamente perfeitas de pinhão manso (Tabelas 2, 3 e 4). Com isso, fica evidenciado o efeito inibitório do endosperma na germinação in vitro do embrião zigótico de pinhão manso.

Resultados semelhantes foram obtidos por HANNACHI et al. (2011), quando esses

Tabela 1 - Resumo da análise de variância para as médias de comprimento da parte aérea (CPA), comprimento da raiz (CR) e número de folhas (NF) de embriões de pinhão manso, submetidos a diferentes condições de germinação (Cg), após diferentes tempos de armazenamento $(\mathrm{T})$

\begin{tabular}{|c|c|c|c|c|}
\hline \multirow{2}{*}{ Fonte de Variação } & \multirow{2}{*}{ GL } & & & \\
\hline & & CPA & $\mathrm{CR}$ & NF \\
\hline Condições de germinação (Cg) & 3 & $35,6872 * *$ & $15,0570 * *$ & $44,69722 * *$ \\
\hline Tempo (T) & 2 & $8,59733 * *$ & $3,19908 * *$ & $2,60833 * *$ \\
\hline $\operatorname{Cg} \times \mathrm{T}$ & 6 & $1,61378 * *$ & $0,81131 \mathrm{~ns}$ & $0,59722 \mathrm{~ns}$ \\
\hline
\end{tabular}

** valor de F significativo em nível de 1\% de probabilidade de erro. ns - valores não significativos.

Ciência Rural, v.44, n.3, mar, 2014. 
Tabela 2 - Comprimento médio da parte aérea de plântulas provenientes de embriões zigóticos isolados ou ligados ao endosperma, obtidos de sementes de pinhão manso recém colhidas (pericarpo amarelo) ou armazenadas por 50 e 100 dias e germinados in vitro, em meio de cultivo de Murashige \& Skoog (MS), adicionados ou não de extratos de endosperma puro ou filtrado. Chapadão do Sul, 2011.

\begin{tabular}{|c|c|c|c|c|}
\hline \multicolumn{2}{|c|}{ Condições de Germinação } & \multirow{2}{*}{$\frac{0}{0,00 \mathrm{cB}}$} & \multirow{2}{*}{$\frac{50}{0,00 \mathrm{cB}}$} & \multirow{2}{*}{$\frac{100}{1,62 \mathrm{cA}}$} \\
\hline $1-$ & Ext. puro (embrião) & & & \\
\hline $2-$ & Ext. filtrado (embrião) & $1,03 \mathrm{bB}$ & $1,13 \mathrm{bB}$ & $2,11 \mathrm{bA}$ \\
\hline $3-$ & Ausente (embrião) & $2,20 \mathrm{aB}$ & $2,42 \mathrm{aB}$ & $2,86 \mathrm{aA}$ \\
\hline 4- & Ausente (embrião+endosperma) & $0,00 \mathrm{cA}$ & $0,00 \mathrm{cA}$ & $0,00 \mathrm{dA}$ \\
\hline
\end{tabular}

Médias seguidas pela mesma letra minúscula na mesma coluna e seguida de letra maiúscula na mesma linha não diferem significativamente pelo teste de Tukey a $5 \%$ probabilidade.

autores, trabalhando com dormência de sementes de oliva selvagem (Olea europaea L. var. sylvestris), observaram que a germinação do embrião isolado foi sempre maior do que das sementes intactas, e que isso pode ser atribuído aos efeitos inibitórios do tegumento e do endosperma na germinação das sementes. Ainda, segundo estes autores, tal dormência pode residir principalmente no endosperma e parcialmente no embrião. Dados apresentados por outros autores também corroboram as observações registradas para pinhão manso, de que a remoção do endosperma traz benefícios para germinação in vitro do embrião, conforme YOU et al. (2005) e MENDES et al. (2008), os quais trabalharam com Eleutherococcus senticosus e Citrus spp, respectivamente.

Adicionalmente, quando o embrião isolado foi colocado em meio de germinação MS contendo extrato Puro (T1) e extrato filtrado (T2) de endosperma, todos os parâmetros analisados sinalizam para inibição química do processo de retomada do crescimento do eixo embrionário, principalmente na presença do extrato puro. Esse efeito tornou-se menor com o armazenamento das sementes (Tabelas 2 e 4), provavelmente, em função da degradação das substâncias inibitórias. Esses resultados indicam que, pelo menos em parte, o processo de inibição que o endosperma parece exercer sobre o embrião deve-se a fatores relacionados à dormência química. Ademais, comparando as respostas dos embriões submetidos aos extratos (T1 e T2) com aquela dos embriões com endosperma intacto (T4), fica evidente que, além da dormência química, o endosperma parece exercer também dormência física contrária à retomada do crescimento in vitro do eixo embrionário de embriões zigóticos de pinhão manso. SREENIVASULU et al. (2009) afirmam que o endosperma de Podophyllum hexandrum inibe temporariamente a germinação da semente desta espécie, semelhante ao verificado para J. curcas no presente trabalho.

Pesquisas sobre o desenvolvimento da semente sinalizam para uma importância do endosperma, não apenas como uma fonte de nutrientes, mas como um integrante do desenvolvimento e do crescimento da semente. Além de que diferentes rotas de sinalização estão sendo descobertas entre o embrião, o endosperma e o tegumento (BERGER et al., 2006). Com isso, os dados obtidos sinalizam a existência dessa estreita relação entre os diferentes componentes da semente de pinhão manso na retomada do processo de desenvolvimento e crescimento do embrião durante o processo germinativo.

Tabela 3 - Médias do comprimento da raiz principal e número de folhas expandidas de plântulas de pinhão manso, oriundas de embriões zigóticos, cultivados em diferentes condições de germinação, em meio de cultivo de Murashige e Skoog (MS). Chapadão do SulMS, 2011.

\begin{tabular}{llcr}
\hline \multicolumn{2}{c}{ Condições de Germinação } & Comprimento raiz (cm) & Folha expandida \\
\hline $1-$ & Ext. puro (embrião) & $0,12 \mathrm{bc}$ & $0,07 \mathrm{~b}$ \\
$2-$ & Ext. filtrado (embrião) & $0,50 \mathrm{~b}$ & $0,23 \mathrm{~b}$ \\
$3-$ & Ausente (embrião) & $1,56 \mathrm{a}$ & $2,53 \mathrm{a}$ \\
$4-$ & Ausente (embrião+endosperma) & $0,00 \mathrm{c}$ & $0,00 \mathrm{~b}$ \\
\hline
\end{tabular}

Médias seguidas pela mesma letra na coluna não diferem significativamente pelo teste de Tukey a 5\% probabilidade. 
Tabela 4 - Médias do comprimento da raiz principal $(\mathrm{cm})$ e número de folhas expandidas de plântulas de pinhão manso, oriundas de embriões zigóticos, extraídos de sementes armazenadas por 0,50 e 100 dias cultivados em meio de cultivo de Murashige e Skoog (MS), em diferentes exposições ao endosperma. Chapadão do Sul-MS, 2011.

\begin{tabular}{lcc}
\hline $\begin{array}{l}\text { Armazenamento } \\
(\text { dias })\end{array}$ & $\begin{array}{c}\text { Comprimento raiz } \\
(\mathrm{cm})\end{array}$ & Número de folhas \\
\hline 0 & $0,36 \mathrm{~b}$ & $0,53 \mathrm{~b}$ \\
50 & $0,40 \mathrm{~b}$ & $0,60 \mathrm{~b}$ \\
100 & $0,87 \mathrm{a}$ & $1,00 \mathrm{a}$ \\
\hline
\end{tabular}

Médias seguidas pela mesma letra na coluna não diferem significativamente pelo teste de Tukey a $5 \%$ probabilidade.

\section{CONCLUSÃO}

A presença do endosperma impede o processo de germinação in vitro de sementes de pinhão manso desprovidas de tegumento, e por conseguinte, sua remoção permite o perfeito desenvolvimento do embrião in vitro, reforçando a ideia de dormência física.

A adição do extrato de endosperma filtrado ou puro no meio de cultivo retarda o desenvolvimento do embrião in vitro, sendo que o tempo de armazenamento da semente reduz os efeitos inibitórios do extrato.

\section{AGRADECIMENTOS}

À Fundação de Apoio ao Desenvolvimento de Ensino, Ciência e Tecnologia do Mato Grosso do Sul (FUNDECT), pela concessão de bolsa de estudos para o segundo autor.

\section{REFERÊNCIAS}

ARRUDA, F.P. et al. Cultivo de pinhão-manso (Jatropha curcas L.) como alternativa para o semi-árido nordestino. Revista de Oleaginosas e Fibrosas, Campina Grande, v.8, p.789-799, 2004. Disponível em: <http://www.cnpa.embrapa.br/rbof/ artigos/812004006_rbof,8\%281\%29,789-799,2004.pdf $>$. Acesso em: 23 maio 2013 .

BERGER, F. et al. Endosperm: an integrator of seed growth and development. Current Opinion in Plant Biology, United Kingdom, v.9, p.664-670, 2006. Disponível em: <http://www. sciencedirect.com/science/article/pii/S1369526606001567>. Acesso em: 23 maio 2013. doi: 10.1016/j.pbi.2006.09.015.

BOORANASRISAK, T. et al. Proteomic evaluation of free fatty acid biosynthesis in Jatropha curcas L. (physic nut) kernel development. African Journal of Biotechnology, Kenya, v.12, n.21, p.31323142, 2013. Disponível em: <http://www.academicjournals.org/ajb/ PDF/pdf2013/22May/Booranasrisak\%20et\%20al.pdf >. Acesso em: 14 jun. 2013. doi: 10.5897/AJB12.1120.

HANNACHI, M. et al. Effects of tegument, endosperm, cold treatment and harvest date on germination of wild olive.
Dendrobiology, Poland, v.65, p.47-54, 2011. Disponível em: $<$ http://www.idpan.poznan.pl/images/stories/dendrobiology/ vol65/65_47_54.pdf>. Acesso em: 23 maio 2013.

HOFFMANN, C.E.F. et al. Atividade alelopática de Nerium oleander L. e Dieffenbachia picta Schott em sementes de Lactuca Sativa L. e Bidens pilosa L. Revista de Ciências Agroveterinárias, Lages, v.6, n.1, p.11-21, 2007. Disponível em: $<$ http://rca.cav.udesc.br/rca_2007_1/hoffmann.pdf $>$. Acesso em: 25 jun. 2013.

IGLESIAS-FERNÁNDEZ, R.; MATILLA, A.J. Genes involved in ethylene and gibberellins metabolism are required for endospermlimited germination of Sisymbrium officinale L. Planta, Germany, v.231, p.653-664, 2010. Disponível em: <http://www.springerlink. com.ez51.periódicos.capes.gov.br/content/g42404m197v0w855/ fulltext.pdf>. Acesso em: 23 maio 2013. doi: 10.1007/s00425009-1073-5.

JØKER, D.; JEPSEN, J. Jatropha curcas L. Seed Leaflet, Humleback, Denmark, n.83, p.1-2, 2003. Disponível em: <http:// curis.ku.dk/portal-life/files/20648145/jatropha_curcas_83.pdf $>$. Acesso em: 23 maio 2013.

LI, M. et al. Establishment of an Agrobacterium-mediated cotyledon disc transformation method for Jatropha curcas. Plant Cell Tissue and Organ Culture, Netherlands, v.92, p.173181, 2008. Disponível em: <http://www.springerlink.com.ez51. periodicos.capes.gov.br/content/v376261831368541/fulltext.pdf $>$. Acesso em: 23 maio 2013. doi: 10.1007/s11240-007-9320-6.

LIU, H. et al. A comparative analysis of embryo and endosperm proteome from seeds of Jatropha curcas. Journal of Integrative Plant Biology, United Kingdom, v.51, n.9, p.850-857, 2009. Disponível em: <www.ncbi.nlm.nih.gov/pubmed/19723244>. Acesso em: 13 jun. 2013. doi: 10.1111/j.1744-7909.2009.00839.x.

MAGIERO, E.C. et al. Efeito alelopático de Artemisia annua L. na germinação e desenvolvimento inicial de plântulas de alface (Lactuca sativa L.) e leiteiro (Euphorbia heterophylla L.). Revista Brasileira de Plantas Medicinais, Botucatu, v.11, n.3, p.317-324, 2009. Disponível em: < http.//www.scielo.br/pdf/rbpm/ v11n3/14>. Acesso em: 25 jun. 2013.

MENDES, R.C. et al. Effect of mechanical treatments on in vitro germination of citrus seeds. Revista Ceres, Viçosa, v.55, n.5, p.445-449, 2008. Disponível em: <http://www.ceres.ufv.br/ CERES/revistas/V55N005P06808.pdf>. Acesso em: 25 jun. 2013.

MISRA,P.etal.Agrobacteriumtumefaciens-mediatedtransformation protocol of Jatropha curcas L. using leaf and hypocotyl segments. Journal of Plant Biochemistry and Biotechnology, India v.21, n.1, p.128-133, 2012. Disponível em: <http://link.springer.com/content/ pdf/10.1007\%2Fs13562-011-0072-3.pdf>. Acesso em: 13 jun. 2013. doi: 10.1007/s13562-011-0072-3.

MUKHERJEE, P.; JHA, T.B. Biotechnological improvement of a biofuel crop - Jatropha curcas. In: WRIGHT, J.H.; EVANS, D.A. (Eds.). New research in biofuels. New York: Nova Science Publishers, 2009. p.31-52.

MURASHIGE, T.; SKOOG, F. A revised medium for rapid growth and biossays with tabacco tissue cultures. Physiologia Plantarum, Weinheim, v.15, n.3, p.473-497, 1962. Available from: <http:// onlinelibrary.wiley.com/doi/10.1111/j.1399-3054.1962.tb08052.x/ abstract>. Accessed: Oct. 30, 2012. doi:10.1111/j.1399-3054.1962. tb08052.x. 
NUNES, C.F. Caracterização de frutos, sementes e plântulas e cultivo de embriões de pinhão manso (Jatropha curcas L.). 2007. 78f. Dissertação (Mestrado em Fitotecnia, Universidade Federal de Lavras, MG.

NUNES, C.F. et al. Diferentes suplementos no cultivo in vitro de embriões de pinhão-manso. Pesquisa Agropecuária Brasileira, Brasília, v.43, n.1, p.9-14, 2008. Disponível em: <http://www. scielo.br/pdf/pab/v43n1/a02v43n1.pdf>. Acesso em: 23 maio 2013.

OLIVEIRA, A.P.A. et al. Inibidores da germinação em sementes de pinhão-manso (Jatropha curcas L.). In: CONGRESSO BRASILEIRO DE PESQUISA EM PINHÃO MANSO, 2009, Brasília, DF. Anais... Brasília: Associação Brasileira de Produtores de Pinhão Manso, 2009. 1 CD.

SATURNINO, H.M. et al. Cultura do pinhão manso (Jatropha curcas L.). Informe Agropecuário, Belo Horizonte, v.26, n.229, p.44-74, 2005.

SEVERINO, L.S. et al. Germinação e crescimento inicial de plântulas de pinhão manso em função do peso da semente. Campina Grande, Embrapa Algodão, 2006, 4p. (Comunicado
Técnico, 309). Disponível em: <http://www.infoteca.cnptia. embrapa.br/bitstream/doc/274845/1/COMTEC309.pdf>. Acesso em: 23 maio 2013.

SREENIVASULU, Y. et al. Endosperm delays seed germination in Podophyllum hexandrum Royle - an important medicinal herb. Seed Science \& Technology, Bassersdorf, Switzerland, v.37, p.1016, 2009.

WINDAUER, L.B. et al. Germination responses to temperature and water potential in Jatropha curcas seeds: a hydrotime model explains the difference between dormancy expression and dormancy induction at different incubation temperatures. Annals of Botany, United Kingdom, v.109, p.265-273, 2012. Disponível em: <http://aob.oxfordjournals.org.ez51.periodicos.capes.gov.br/ content/109/1/265.full.pdf + html $>$. Acesso em: 23 maio 2013. doi: 10.1093/aob/mcr242.

YOU, X-L. et al. Rapid in vitro germination of zygotic embryos via endosperm removal in Eleutherococcus senticosus. Journal of Plant Biotechnology, v.7, n.1, p.75-80, 2005. Disponível em: $<$ http://www.cabi.org/cabdirect/FullTextPDF/2005/20053222127. pdf>. Acesso em: 23 jun. 2013. 